\title{
A database of multi-year (2004-2010) quality-assured surface solar hourly irradiation measurements for the Egyptian territory
}

\author{
Mohamed Korany ${ }^{1}$, Mohamed Boraiy ${ }^{2}$, Yehia Eissa ${ }^{3,4}$, Youva Aoun ${ }^{4}$, Magdy M. Abdel Wahab ${ }^{5}$, \\ Stéphane C. Alfaro ${ }^{6}$, Philippe Blanc ${ }^{4}$, Mossad El-Metwally ${ }^{7}$, Hosni Ghedira ${ }^{3}$, Katja Hungershoefer ${ }^{8}$, \\ and Lucien Wald ${ }^{4}$ \\ ${ }^{1}$ Egyptian Meteorological Authority, Cairo, Egypt \\ ${ }^{2}$ Physics and Mathematical Engineering Department, Faculty of Engineering, \\ Port Said University, Port Said, Egypt \\ ${ }^{3}$ Masdar Institute, Research Center for Renewable Energy Mapping and Assessment, \\ P.O. Box 54224, Abu Dhabi, UAE \\ ${ }^{4}$ MINES ParisTech, PSL Research University, O.I.E. - Centre Observation, Impacts, Energy, \\ CS 10207 - 06904 Sophia Antipolis CEDEX, France \\ ${ }^{5}$ Astronomy and Meteorology Department, Faculty of Science, Cairo University, Cairo, Egypt \\ ${ }^{6}$ Laboratoire Inter-universitaire des Systèmes Atmosphériques, Universités de Paris-Est Créteil et \\ Paris-Diderot, France \\ ${ }^{7}$ Physics Department, Faculty of Science, Port Said University, Port Said, Egypt \\ ${ }^{8}$ Deutscher Wetterdienst, Offenbach, Germany \\ Correspondence to: Stéphane Alfaro (alfaro@lisa.u-pec.fr)
}

Received: 6 July 2015 - Published in Earth Syst. Sci. Data Discuss.: 9 September 2015

Revised: 18 February 2016 - Accepted: 21 February 2016 - Published: 1 March 2016

\begin{abstract}
A database containing the global and diffuse components of the surface solar hourly irradiation measured from 1 January 2004 to 31 December 2010 at eight stations of the Egyptian Meteorological Authority is presented. For three of these sites (Cairo, Aswan and El-Farafra), the direct component is also available. In addition, a series of meteorological variables including surface pressure, relative humidity, temperature, wind speed and direction is provided at the same hourly resolution at all stations. The details of the experimental sites and instruments used for the acquisition are given. Special attention is paid to the quality of the data and the procedure applied to flag suspicious or erroneous measurements is described in detail. Between 88 and $99 \%$ of the daytime measurements are validated by this quality control. Except at Barrani where the number is lower (13500), between 20000 and 29000 measurements of global and diffuse hourly irradiation are available at all sites for the 7-year period. Similarly, from 9000 to 13000 measurements of direct hourly irradiation values are provided for the three sites where this component is measured. With its high temporal resolution this consistent irradiation and meteorological database constitutes a reliable source to estimate the potential of solar energy in Egypt. It is also adapted to the study of high-frequency atmospheric processes such as the impact of aerosols on atmospheric radiative transfer. It is planned to update regularly the current 2004-2010 database, which has been placed on the PANGAEA repository (doi:10.1594/PANGAEA.848804) and contains the individual meteorological and irradiation data files of the eight stations.
\end{abstract}




\section{Introduction}

With the development of solar-based renewable energy technologies, national meteorological services must face increasing demands for reliable data on solar resource. Complete and accurate solar radiation data for specific regions are also indispensable for a large variety of solar-energy-related studies. The surface solar irradiation (SSI), i.e. the downwelling broadband solar irradiation received at ground level on a horizontal plane, and its diffuse and direct components are measured by means of pyranometers and pyrheliometers (WMO, 2008). Pyranometers are hemispherical sensors measuring the global irradiation on a horizontal plane, denoted by the variable $G$. Shaded pyranometers measure the diffuse irradiation on a horizontal plane, $D$. Pyrheliometers, comprised of thermopile sensors and a Sun-tracking mechanism, measure the direct (or beam) irradiation incident from the Sun on a normal plane, $B_{\mathrm{n}}$. The varying aperture (or opening) halfangles of the different pyrheliometeric systems, normally between $2.5^{\circ}$ and $5^{\circ}$, means they are also measuring the radiation surrounding the solar disc, i.e. the circumsolar radiation (Blanc et al., 2014).

Measuring the SSI and its components is more difficult than other meteorological variables. Systematic errors due to the instruments themselves exist (e.g. Muneer and Fairooz, 2002; Younes et al., 2005), but the most important ones are usually random and due to operational causes such as maintenance and instrument reading. Therefore, one of the major concerns of operational radiometric networks is to perform a rigorous quality control (QC) on the measurements (e.g. Journée and Bertrand, 2011; Moradi, 2009; Roesch et al., 2011). This is an indispensable step before further processing of the data.

In order to provide the large community of potential users with high quality SSI data, the Egyptian Meteorological Authority (EMA) started establishing in the 1960s a network of stations measuring the global SSI and its diffuse and direct components, as well as more common surface meteorological variables. Currently, this network includes more than 10 sites.

The aim of this paper is to describe the SUSIE (SUrface Solar Irradiance in Egypt for energy production) database elaborated in the framework of the eponymous Egyptian/French project. The database covers the period 20042010 and includes the quality-checked hourly measurements of the SSI components performed at eight EMA stations (Fig. 1). These stations were selected for being representative of the different types of Egyptian climates (Diabaté et al., 2004), namely "coastal" (Matruh, Barrani), arid Sinai Peninsula (El-Arish), "urban" (Cairo), "Nile valley and upper Egypt" (Asyut and Aswan) and "desert" (El-Kharga and El-Farafra). For all sites, meteorological variables such as air temperature, pressure, wind direction/speed and humidity are also included in the database.
Measurements are currently going on at the EMA stations and SUSIE was an opportunity to make measurements available to a wide audience. Note that for the moment no SSI data are proposed after 2010 because EMA was unable to attend the World Meteorological Organization (WMO) International Pyrheliometer Comparison (IPC-XI) held at the World Radiation Center (WRC) in Davos in SeptemberOctober 2010 and calibrate its absolute reference pyrheliometer, namely the self-calibrating Absolute Cavity Pyrheliometer Model HF No. 31103. Therefore, the EMA cannot consider its post-2010 measurements reliable before this reference instrument is calibrated again in the frame of the 12th International Pyrheliometer Comparison (IPC-XII) in September-October 2015 at the WRC and a correction is designed for the data from 2011 to 2015.

This paper is organized as follows: the study area and the available ground measuring instruments are described in Sect. 2, the QC procedures applied to the SSI measurements are detailed in Sect. 3, their results and the structure of SUSIE database are given in Sect. 4. Finally, Sect. 5 is dedicated to the summary and perspectives. The quality-checked database is available in PANGAEA under Creative Commons Attribution 3.0 Unported International Public License (CC-BY 3.0).

\section{Ground stations and measurements}

\subsection{Location of the measurement sites}

Table 1 contains the names, WMO number and geographical characteristics (latitude, longitude, altitude, type of climate) of the eight sites reported in Fig. 1 and whose measurements in the period 2004-2010 were considered to build the SUSIE database. These sites and their surroundings are briefly described below.

Sidi Barrani (hereinafter referred to more simply as Barrani): situated in Lower Egypt along the north coast, the site is $500 \mathrm{~m}$ away from the Mediterranean coast. The instruments are located on a small hill outside the village of Sidi Barrani and in an open area. The soil around the measurement site is spread with numerous calcareous rocks the size of a fist.

Mersa Matruh (Matruh, hereinafter): also situated in Lower Egypt along the north coast and $\sim 3000 \mathrm{~m}$ away from the Mediterranean coast. The instruments are located on the roof of a two-story building at the local airport. The surroundings are low residential buildings. No appreciable interception of the sky exists.

El-Arish: the station lies in the northeastern part of the arid Sinai Peninsula. The instruments are set up on the roof of the meteorological office, away from the town centre. The station is in the middle of olive farms and close to the ElArish airport. The site has an open sky dome.

Cairo: the instruments are located on the roof of the main building of the EMA Headquarters. The site is of the urban 


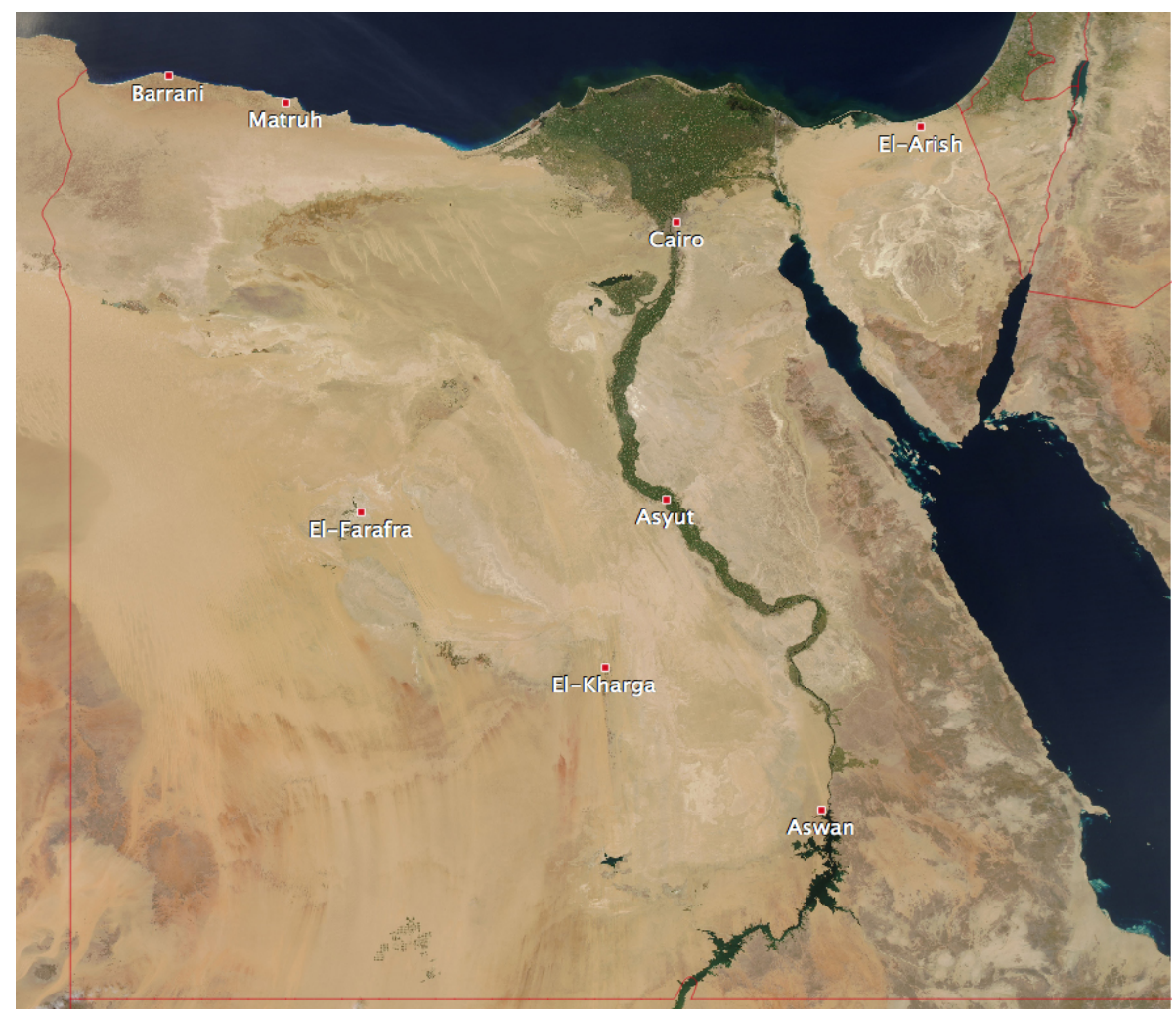

Figure 1. Location of the eight surface stations of the Egyptian Meteorological Authority (EMA) whose data are included in the SUSIE database.

Table 1. Name, WMO\#, Location (Lat-Long), altitude (m), SSI components measured ( $B_{\mathrm{n}}$ : direct at normal incidence; $D$ : diffuse; $G$ : global), and type of climate for the eight sites.

\begin{tabular}{lrrrrll}
\hline Site & WMO\# & Lat $^{\circ}$ & Long $^{\circ}$ & Alt $(\mathrm{m})$ & SSI components & Station type \\
\hline Barrani & 62303 & 31.60 & 26.00 & 23.7 & $G, D$ & Mediterranean climate \\
Matruh & 62306 & 31.33 & 27.22 & 25 & $G, D$ & Mediterranean climate \\
El-Arish & 62337 & 31.08 & 33.82 & 27.2 & $G, D$ & Mediterranean climate \\
Cairo & 62371 & 30.08 & 31.28 & 34.4 & $G, D, B_{\mathrm{n}}$ & Urban-influenced climate \\
El-Kharga & 62435 & 25.45 & 30.53 & 77.8 & $G, D$ & Western desert climate \\
El-Farafra & 62423 & 27.06 & 27.99 & 82.2 & $G, D, B_{\mathrm{n}}$ & Western desert climate \\
Asyut & 62393 & 27.2 & 31.17 & 52 & $G, D$ & Desert Nile climate \\
Aswan & 62414 & 23.97 & 32.78 & 192.5 & $G, D, B_{\mathrm{n}}$ & Desert Nile climate \\
\hline
\end{tabular}

type, surrounded by high buildings and a heavy traffic load. In addition, two large industrial areas, Shubra El-Kheima and Helwan, are located north and south, respectively, of the measurement site.

El-Kharga: the oasis is inside the Western Desert. The station itself is located at the limit of the oasis in an agricultural research centre around which bare sandy surfaces with scattered shrubs can be observed. No appreciable interception of the sky exists within the field of view of the measuring instruments.

El-Farafra: this small oasis is located approximately $450 \mathrm{~km}$ to the southwest of Cairo and $480 \mathrm{~km}$ south of the
Mediterranean Sea in a part of the western Egyptian desert known as the "White Desert". The instruments are located on the roof of the two-story building of EMA station. The site is located east of the village of El-Farafra, in an extremely flat, open area deprived of any obstacles. According to the classification of Diabaté et al. (2004), the area is characterized by a dry desert climate.

Asyut is located in Upper Egypt along the Nile, and exhibits a dry desert climate. The instruments are installed over a three-story building inside the campus of Asyut University near cultivated fields of the Agricultural Research Centre. No appreciable interception of the sky exists. 
Aswan is also situated in Upper Egypt and it exhibits a dry desert climate. The instruments are installed over a two-story building inside the premises of the Aswan military airport. The site is surrounded by sandy surfaces with sparse rocks of varying sizes.

\subsection{Irradiation measurements}

\subsubsection{Instruments and data storage}

SSI measurements are not performed with the same types of pyranometers and pyrheliometers at the eight sites. Table 2a$h$ contains the period of measurements - note that the measurements at Barrani and El-Farafra did not start before January and August 2005, respectively - and the details of the instruments. Data-loggers scan the signals from the radiation sensors at least every minute. However, in order to increase their storage capacity, these initial data are stored as hourly averages.

\subsubsection{Instrument maintenance, calibration and performance}

Measurements of the global SSI are made with pyranometers. The properties of concern when evaluating the accuracy and quality of the radiation measurements are the sensitivity, stability, response time, cosine response, azimuth response, linearity, temperature response and spectral response (Wald et al., 2000; ISO-9060, 1990). Deviations are caused primarily by the directional sensitivity of the individual receiver surfaces and by effects of the glass dome covering the upward-facing sensor (Geiger et al., 2002). This dome must be cleaned regularly to avoid soiling of its surface, especially at the desert stations where deposition of wind-blown dust is an acute problem. Other errors may result from inaccurate horizontal adjustment of the receiver surface, moisture inside the dome, etc. Though smaller relative uncertainties can be achieved for daily irradiation (WMO, 2008), in the case of hourly irradiation the relative uncertainties at the $66 \%$ confidence level are about 3, 5 and $20 \%$ for operational pyranometers of high, good and moderate quality, respectively. T PSP and NIP instruments (see Table 2) are of the highquality types and the relative uncertainty on the hourly $G$ and $B_{\mathrm{n}}$ is less than $3 \%$. The $8-48$ instrument is of the goodquality type, and the relative uncertainty on $D$ is in the range 3 to $5 \%$.

The shading-unshading method (WMO, 1981; McArthur, 2004) is used to calibrate the pyranometers every year by comparison against the EMA reference Pyrheliometer HF 31103, itself being calibrated every 5 years at the World Radiometric Reference (WRR), at Davos in Switzerland (WMO/TD No. 1320, 2006). In order to minimize the uncertainties further, the measurements performed by the pyranometers are corrected to account for: (1) thermal offsets, (2) cosine response, and (3) temperature sensitivity of the calibration constant. These corrections follow the
WRC $(1985,1995)$ guidelines. The pyrheliometers and pyranometers used at the EMA stations are traceable to the World Radiometric Reference (WRR) standards.

\subsection{Meteorological variables}

Basic meteorological variables, namely the relative humidity, mean sea level pressure, dry-bulb temperature, wet-bulb temperature, wind direction, wind speed and cloud amount are also measured at the EMA sites. Except for cloud amount, measurements are performed at the frequency of $1 \mathrm{~Hz}$ for the $10 \mathrm{~min}$ preceding each hour and their averages are stored by the data-loggers.

All measurements are performed in agreement with the WMO requirements. Mercury thermometers manufactured by R. Fuess and Theodor Friedrichs, which count among the most accurate meteorological thermometers (WMO, 2008), are used for routine observations of the air, wet-bulb and dry-bulb temperatures. Based on the recommendation of the Commission for Instruments and Methods of Observation, several regional associations of WMO have set up regional instrument centres (RICs) to maintain standards and provide advice (WMO/CIMO, 1985). Cairo (Egypt) is one of those RICs for RA I (Africa). Their terms of reference and locations are given in WMO (2008, Annex 1.A).

The operational instruments for measuring atmospheric pressure are mercury (R. Fuess, type 11a-9) barometers, and Short and Mason barographs are used for continuous pressure recording. Surface wind characteristics (speed and direction) are monitored with Munro cup or propeller anemometers. Finally, the measurements of the cloud amount are made by visual observation according to the Code table 2700 in WMO (2010).

\section{Details of the quality control applied to the data}

The EMA is particularly aware of the importance of the quality assurance and management of its observing systems. In spite of the quality of the instruments used and of the dedication of the personnel who calibrate, maintain and operate them, measurement errors are still possible. Therefore, quality control (QC) procedures aiming at flagging suspicious values are applied to the measurements of solar radiation and other meteorological variables.

\subsection{Meteorological variables}

Beside the care brought on site to the maintenance of the instruments by qualified personnel, the surface meteorological hourly data must pass a classical quality check (validation and reviewing) before being accepted into the database and archived. This quality check comprises the four following steps: 
Table 2. Details of the set of instruments implemented at the eight experimental sites. Their accuracy (in $\left.\mathrm{mV} \mathrm{cal}^{-1} \mathrm{~cm}^{-2} \mathrm{~min}^{-1}\right)$ and working periods are also reported.

\begin{tabular}{|c|c|c|c|c|c|}
\hline \multirow[t]{2}{*}{ Station } & \multirow[t]{2}{*}{ SSI } & \multirow[t]{2}{*}{ Model } & \multirow[t]{2}{*}{ Accuracy } & \multicolumn{2}{|c|}{ Working period } \\
\hline & & & & from & to \\
\hline \multirow[t]{6}{*}{ (a) Barrani } & $G$ & PSP & 6.324 & Before & 31 May 2004 \\
\hline & $D$ & $8-48$ & 4.782 & Before & 31 May 2004 \\
\hline & $G$ & PSP & 6.523 & 31 May 2004 & 4 November 2008 \\
\hline & $D$ & $8-48$ & 8.122 & 31 May 2004 & 4 November 2008 \\
\hline & $G$ & PSP & 6.803 & 4 November 2008 & 21 September 2011 \\
\hline & $D$ & $8-48$ & 7.943 & 4 November 2008 & 21 September 2011 \\
\hline \multirow[t]{5}{*}{ (b) Matruh } & $G$ & PSP & 7.894 & before & 1 June 2004 \\
\hline & $D$ & $8-48$ & 6.968 & before & 1 June 2004 \\
\hline & $G$ & PSP & 7.150 & 1 June 2004 & 5 November 2008 \\
\hline & $D$ & $8-48$ & 8.251 & 1 June 2004 & 5 November 2008 \\
\hline & $G$ & PSP & 7.265 & 5 November 2008 & 22 September 2011 \\
\hline \multirow[t]{11}{*}{ (c) El-Arish } & $G$ & PSP & 7.204 & 27 May 2003 & 17 July 2005 \\
\hline & $D$ & $8-48$ & 8.070 & 27 May 2003 & 17 July 2005 \\
\hline & $G$ & PSP & 6.064 & 17 July 2005 & 28 February 2008 \\
\hline & $D$ & $8-48$ & 8.260 & 17 July 2005 & 28 February 2008 \\
\hline & $G$ & PSP & 8.116 & 28 February 2008 & 30 April 2009 \\
\hline & $D$ & $8-48$ & 7.469 & 28 February 2008 & 30 April 2009 \\
\hline & $G$ & PSP & 6.551 & 30 April 2009 & 6 August 2010 \\
\hline & $G$ & PSP & 6.155 & 6 August 2010 & 29 November 2010 \\
\hline & $D$ & $8-48$ & 6.401 & 6 August 2010 & 29 November 2010 \\
\hline & $G$ & PSP & 5.692 & 29 November 2010 & 31 October 2011 \\
\hline & $D$ & $8-48$ & 6.995 & 29 November 2010 & 31 October 2011 \\
\hline \multirow[t]{12}{*}{ (d) Cairo } & $G$ & PSP & 7.108 & before & 9 February 2002 \\
\hline & $D$ & $8-48$ & 8.513 & before & 7 February 2002 \\
\hline & $B_{\mathrm{n}}$ & NIP & 7.608 & before & 9 February 2002 \\
\hline & $G$ & PSP & 7.108 & 9 February 2002 & 21 April 2005 \\
\hline & $D$ & $8-48$ & 8.513 & 7 February 2002 & 21 April 2005 \\
\hline & $B_{\mathrm{n}}$ & NIP & 7.720 & 9 February 2002 & 25 April 2005 \\
\hline & $G$ & PSP & 7.108 & 21 April 2005 & 13 July 2008 \\
\hline & $D$ & $8-48$ & 8.513 & 21 April 2005 & 13 July 2008 \\
\hline & $B_{\mathrm{n}}$ & NIP & 6.082 & 25 April 2005 & 13 July 2008 \\
\hline & $G$ & $\mathrm{~K} \& \mathrm{Z}$ & 8.115 & 13 July 2008 & 10 May 2012 \\
\hline & $D$ & $\mathrm{~K} \& \mathrm{Z}$ & 8.038 & 13 July 2008 & 8 February 2012 \\
\hline & $B_{\mathrm{n}}$ & $\mathrm{K} \& \mathrm{Z}$ & 7.264 & 13 July 2008 & 8 February 2012 \\
\hline \multirow[t]{6}{*}{ (e) El-Kharga } & $G$ & PSP & 6.707 & 22 September 2003 & 5 November 2005 \\
\hline & $D$ & $8-48$ & 8.144 & 22 September 2003 & 5 November 2005 \\
\hline & $G$ & PSP & 6.307 & 5 November 2005 & 28 December 2008 \\
\hline & $D$ & $8-48$ & 8.730 & 5 November 2005 & 28 December 2008 \\
\hline & $G$ & PSP & 7.168 & 28 December 2008 & 20 April 2011 \\
\hline & $D$ & $8-48$ & 8.122 & 28 December 2008 & 20 April 2011 \\
\hline \multirow[t]{9}{*}{ (f) El-Farafra } & $G$ & PSP & 6.410 & 20 August 2005 & 19 April 2007 \\
\hline & $D$ & $8-48$ & 7.330 & 20 August 2005 & 19 April 2007 \\
\hline & $B_{\mathrm{n}}$ & NIP & 7.608 & 20 August 2005 & 20 April 2007 \\
\hline & $G$ & PSP & 6.080 & 19 April 2007 & 23 February 2009 \\
\hline & $D$ & $8-48$ & 8.201 & 19 April 2007 & 23 February 2009 \\
\hline & $B_{\mathrm{n}}$ & NIP & 7.230 & 20 April 2007 & 22 February 2009 \\
\hline & $G$ & Eko802 & 7.030 & 23 February 2009 & 16 May 2011 \\
\hline & $D$ & $8-48$ & 8.901 & 23 February 2009 & 16 May 2011 \\
\hline & $B_{\mathrm{n}}$ & NIP & 7.068 & 22 February 2009 & 15 May 2011 \\
\hline
\end{tabular}


Table 2. Continued.

\begin{tabular}{llllll}
\hline Station & SSI & Model & Accuracy & \multicolumn{2}{c}{ Working period } \\
\cline { 5 - 6 } & & & & from & to \\
\hline (g) Asyut & $G$ & PSP & 6.269 & 21 September 2003 & 4 November 2005 \\
& $D$ & $8-48$ & 7.779 & 21 September 2003 & 4 November 2005 \\
& $G$ & PSP & 6.043 & 4 November 2005 & 27 December 2008 \\
& $D$ & $8-48$ & 7.747 & 4 November 2005 & 27 December 2008 \\
& $G$ & PSP & 6.521 & 27 December 2008 & 29 January 2011 \\
& $D$ & $8-48$ & 6.972 & 27 December 2008 & 29 January 2011 \\
\hline (h) Aswan & $G$ & PSP & 5.572 & 12 October 2003 & 7 November 2006 \\
& $D$ & $8-48$ & 7.073 & 12 October 2003 & 7 November 2006 \\
& $B_{\mathrm{n}}$ & NIP & 5.072 & 12 October 2003 & 7 November 2006 \\
& $G$ & PSP & 6.375 & 7 November 2006 & 25 July 2008 \\
& $D$ & $8-48$ & 8.261 & 7 November 2006 & 25 July 2008 \\
& $B_{\mathrm{n}}$ & NIP & 5.603 & 7 November 2006 & 20 October 2011 \\
& $G$ & PSP & 5.678 & 25 July 2008 & 20 October 2011 \\
& $D$ & $8-48$ & 7.356 & 25 July 2008 & 20 October 2011 \\
& $B_{\mathrm{n}}$ & NIP & 5.890 & 25 July 2008 & 20 October 2011 \\
\hline
\end{tabular}

- Highly experienced observers screen the records of hourly data. If they detect any logical error, they correct them.

- The reviewed records are sent to the central mainframe for the data entry.

- Computer programs test the internal self-consistency of the data sets and print a list of the suspicious data.

- The data entry errors detected in the previous phase of the checking procedure are corrected.

Note that some rare outliers or suspicious data (for instance null values of $T_{\text {dry }}$ recorded at Barrani in the first half of 2009) might still be present in the meteorological data sets after these corrections.

\subsection{SSI components}

After a visual observation of the data sets of the SSI components to detect and remove periods of obviously erroneous measurements, the data sets are submitted to the QC. This $\mathrm{QC}$ is a succession of tests which result in flagging data as "successfully passed" (flag $=0)$ or "failed" (flag $=1)$ depending on the result of the test. In essence, the QC of the radiometric observations includes limits within which data are expected to lie for being acceptable. These tests are guided either by physical reasoning - detecting physically impossible events - or by criteria based on the expected statistical variability of the data - detecting very rare and thus questionable events. Furthermore, they either treat the various solar radiation parameters separately or compare them to each other. De Miguel et al. (2001), Geiger et al. (2002), Long and Dutton (2002), Muneer and Fairooz (2002), and Younes et al. (2005) have proposed such tests, which have been adopted here for hourly irradiation. The measurements have units of $\mathrm{MJ} \mathrm{m}^{-2}$. Denoting $\theta_{\mathrm{S}}$ the solar zenith angle, $E_{0}$ and $E_{0, \mathrm{n}}$ the hourly irradiation at top of atmosphere received on a horizontal surface, respectively at normal incidence, the conditions to pass are:

$$
\begin{aligned}
G> & \max \left(0.03 E_{0}, 0.0036 \mathrm{MJ} \mathrm{m}^{-2}\right) \\
G< & \min \left(1.2 E_{0, \mathrm{n}}, 1.5 E_{0} \cos \left(\theta_{\mathrm{S}}\right)^{0.2}+0.36 \mathrm{MJ} \mathrm{m}^{-2},\right. \\
& \left.\quad 1.2 E_{0} \cos \left(\theta_{\mathrm{S}}\right)^{0.2}+0.18 \mathrm{MJ} \mathrm{m}^{-2}\right) \\
D & >\max \left(0.03 E_{0}, 0.0036 \mathrm{MJ} \mathrm{m}^{-2}\right) \\
D & <\min \left(0.8 E_{0, \mathrm{n}}, 0.95 E_{0} \cos \left(\theta_{\mathrm{S}}\right)^{0.2}+0.18 \mathrm{MJ} \mathrm{m}^{-2},\right. \\
& \left.0.75 E_{0} \cos \left(\theta_{S}\right)^{0.2}+0.108 \mathrm{MJ} \mathrm{m}^{-2}\right) \\
B_{\mathrm{n}} & >0.0036 \mathrm{MJ} \mathrm{m}{ }^{-2} \\
B_{\mathrm{n}} & <\min \left(E_{0, \mathrm{n}}, 0.95 E_{0, \mathrm{n}} \cos \left(\theta_{S}\right)^{0.2}+0.036 \mathrm{MJ} \mathrm{m}^{-2}\right) .
\end{aligned}
$$

For $G, D$ and $B_{\mathrm{n}}$ measured at Aswan, Cairo and El-Farafra, and satisfying the aforementioned QC procedures, an additional "consistency check" is performed. This test flags out any measurement for which the measured and computed $G$ do not agree with each other within specified limits (Roesch et al., 2011):

$0.92 \leq\left(B_{\mathrm{n}} \cos \left(\theta_{\mathrm{S}}\right)+D\right) / G \leq 1.08$ if $\theta_{\mathrm{S}}>75^{\circ}$

$0.85 \leq\left(B_{\mathrm{n}} \cos \left(\theta_{\mathrm{S}}\right)+D\right) / G \leq 1.15$ otherwise.

Practically, $E_{0}, E_{0, \mathrm{n}}$ and $\theta_{\mathrm{S}}$ were obtained from the McClear service available at the SoDa service (www.soda-pro.com; 
Table 3. Duration of the period 2004-2010 (in hours), numbers of available (non-missing, non-night, non-suspicious) data for $G, D$ and $B_{\mathrm{n}}$. The proportion of available measurements having passed the quality check is also reported.

\begin{tabular}{|c|c|c|c|c|c|c|c|}
\hline \multirow[b]{2}{*}{ Site } & \multirow[b]{2}{*}{ Hours } & \multicolumn{2}{|c|}{$G$} & \multicolumn{2}{|c|}{$D$} & \multicolumn{2}{|c|}{$B_{\mathrm{n}}$} \\
\hline & & Data & $\%$ Pass & Data & $\%$ Pass & Data & $\%$ Pass \\
\hline Barrani & 61368 & 13543 & 89.7 & 13427 & 91.8 & - & - \\
\hline Matruh & 61368 & 24177 & 91.9 & 23685 & 92.4 & - & - \\
\hline El-Arish & 61368 & 20998 & 95.5 & 20344 & 95.8 & - & - \\
\hline Cairo & 61368 & 23481 & 98.5 & 22284 & 97.4 & 12939 & 88.7 \\
\hline El-Kharga & 61368 & 27128 & 96.1 & 27439 & 97.5 & - & - \\
\hline El-Farafra & 61368 & 19853 & 97.2 & 18738 & 91.8 & 8986 & 93.1 \\
\hline Asyut & 61368 & 28542 & 98.4 & 28473 & 98.9 & - & - \\
\hline Aswan & 61368 & 21342 & 96.4 & 21343 & 94.8 & 10827 & 96.7 \\
\hline
\end{tabular}

Gschwind et al., 2006). Within a few clicks, the McClear service delivers time series of the SSI components that should be observed if the sky were clear for the site of interest (Lefèvre et al., 2013). It also provides precise values of $E_{0}$ using an accurate algorithm for computing $\theta_{\mathrm{S}}$ (Blanc and Wald, 2012). Estimates of SSI in McClear are performed with a $1 \mathrm{~min}$ step; estimates may be then aggregated for various durations. Here, hourly values for $E_{0}$ and the SSI components for clear-sky $G_{\text {clear }}, D_{\text {clear }}, B_{\text {clear }}$ and $B_{\text {clear,n }}$ were requested, where $B_{\text {clear }}$ denotes the direct SSI on a horizontal surface. Unfortunately, the McClear service does not provide estimates of $\theta_{\mathbf{S}}$ for each hour. As $\theta_{\mathbf{S}}$ varies greatly within an hour, an effective $\theta_{\mathrm{S}}$ was computed for each hour (Blanc and Wald, 2016):

$\cos \left(\theta_{\mathrm{S}}\right)=B_{\text {clear }} / B_{\text {clear, } \mathrm{n}}$

$E_{0, \mathrm{n}}=E_{0} / \cos \left(\theta_{\mathrm{S}}\right)$.

\section{Results}

\subsection{Results of the quality check}

Theoretically, the maximal number of data that can be acquired between 1 January 2004 and 31 December 2010 is equal to the number of hours (61368) in this period. Among these, approximately half are nighttime hours during which measurements are performed but give a null result that do not meet the minimum value requirement (see Eqs. 1, 3 and 5 above) of the QC. They are flagged accordingly. In addition, several daytime values are missing in the sets of original data because of instrumental problems or maintenance operations. In the case of El-Farafra and Barrani, the measurement period did not start in 2004 but in 2005, which contributes to increase significantly the number of missing data. In ElArish, the data of 2010 were also discarded from the start after a visual screening because there was obviously a problem with them. Table 3 reports for each station and for each irradiation component $\left(G, D\right.$ and $\left.B_{\mathrm{n}}\right)$ the total duration (in hours) of the measurement period, the number of available (non-night and non-missing) data before QC, and the proportion of this available data that passed the QC.

Even though the number of missing data is significantly larger at Barrani than elsewhere, the proportion of existing data validated by the QC (between 88.7 and $98.8 \%$ ) is remarkably large at all sites, which emphasizes the excellent quality of the measurements performed at the EMA stations. Therefore, at seven of the eight stations, from about 18000 to $28000 G$ and $D$ hourly values passed the QC successfully and are included in the final SUSIE database. Note that these figures correspond approximately to between 60 and $93 \%$ of the total number of daytime hours and therefore to the theoretical maximum of possible data in this 7-year period. In the case of $B_{\mathrm{n}}$, the number of valid data is smaller but still $>10000$ at Aswan and Cairo, and a little less (8360) at ElFarafra because the measurement period is shorter.

\subsection{The SUSIE database: description and where to access it}

For each of the eight surface stations, one file containing the hourly meteorological observations and another containing the hourly components of the surface irradiation performed in parallel between 2004 and 2010 can be downloaded from the Pangaea website (http://www.pangaea.de/) using a unique identifier (doi:10.1594/PANGAEA.848804). Note that to avoid any risk of confusion, two time stamps are given in UT: one at the beginning, and the other at the end, of the measuring hour. The meteorological files are selfexplanatory and contain 11 columns in which one can find the average, start and end times of the measurements, the relative humidity (in \%), the surface pressure (in $\mathrm{hPa}$ ), the dryand wet-bulb temperatures $\left(\right.$ in ${ }^{\circ} \mathrm{C}$ ), the wind direction (in ${ }^{\circ}$, and increasing clockwise with $0^{\circ}$ denoting the wind blowing from the north), the wind speed (in $\mathrm{m} \mathrm{s}^{-1}$ ) and the cloud fraction (in okta).

The irradiation files are organized chronologically as the meteorological ones. They contain the measurements (in $\mathrm{MJ} \mathrm{m}^{-2}$ ) of the global $(G)$, diffuse $(D)$ and for the three 
(a)
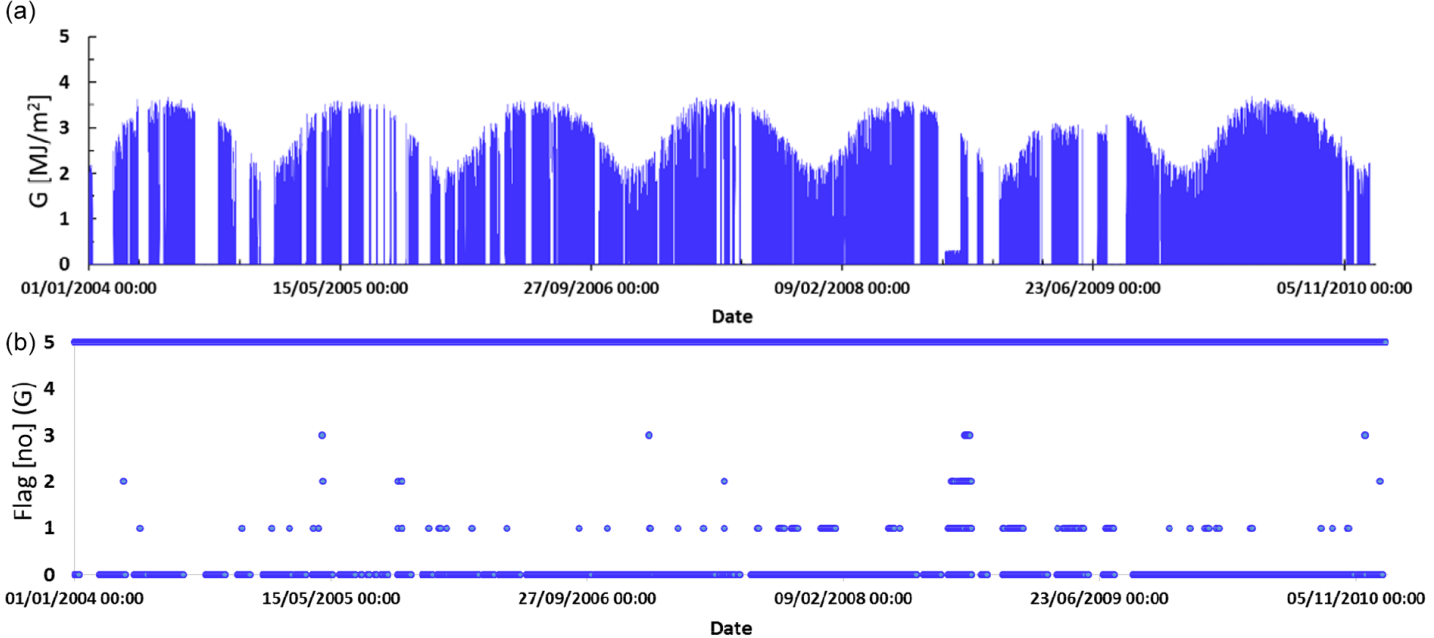

Figure 2. Temporal variation of the hourly global horizontal irradiation $\left(G\right.$, in $\mathrm{MJ} \mathrm{m}^{-2}$ ) measured from 1 January 2004 to $31 \mathrm{December}$ 2010 at the Cairo station (a), and corresponding values of the flags allotted after the different tests of the quality tests (b).

stations where it is measured, the direct normal $\left(B_{\mathrm{n}}\right)$ irradiations. Missing values are left blank. Each available measurement is flagged " 0 " if it has successfully passed the QC and the visual screening. Otherwise, a flag is allotted whose value indicates the reason why the data were not considered as valid. More precisely, " 1 " means that the measurement is outside the range of expected extreme values, "2" that the measurement is greater than rarely observed values, " 3 " that the measurement is greater than rarely observed values and outside the range of expected extreme values. Flag "4" indicates that though having passed the QC successfully, the measurement is suspicious because further visual screening casts doubts on its validity. Flag "5" corresponds to night values. Finally, when $G, D$ and $B_{\mathrm{n}}$ are available simultaneously, which is only possible at the Cairo, Aswan and ElFarafra stations, a last consistency flag of " 0 " if passed, or " 1 " otherwise is attributed. For illustrating the quality of the measurements, the variation with time of $G$ measured at the Cairo station and the associated values of the different flags are plotted in Fig. 2a and b, respectively. As already reported in Table 3 , only a very small fraction $(1.5 \%)$ of the available data does not pass the quality check.

\section{Summary and perspectives}

A homogeneous database of hourly meteorological variables and surface solar irradiation components has been assembled. The data cover the period January 2004 to December 2010 and originate from eight surface stations representative of the variety of geographical (coastal, urban and desert) conditions in the Egyptian territory. These quality-checked data are available online at doi:10.1594/PANGAEA.848804. The data provide an insight to the spatial and temporal variability of the global, diffuse and direct components of the solar irradiation and thus constitute a precious tool for the estimation of the potential of solar energy in Egypt. Because of their high temporal resolution, the data are also adapted to atmospheric studies such as the study of the impact of aerosols on atmospheric radiative transfer. In the near future, it is planned to complete regularly the present 2004-2010 database, starting with the data of the period 2011-2015, as soon as the reference radiometer is recalibrated. Thanks to this continued acquisition, longer and more adapted to climate studies time series will eventually become available in this part of the world where they are currently very scarce.

Acknowledgements. This work took place within the frameworks of the SUSIE (SUrface Solar Irradiance in Egypt for energy production) project (no. 5404) co-funded by the Science and Technology Development Fund (STDF) of Egypt and the French AIRD, and of the MISRA (MIsr Solar Radiation Atlas) project funded by the French Ministry of Foreign Affairs and the UAE government. The authors thank all personnel of the Egyptian Meteorological Authority who installed and maintained the stations in Egypt. The background image of Fig. 1 was taken from the NASA Worldview (https://earthdata.nasa.gov/labs/worldview/) website.

Edited by: D. Carlson

\section{References}

Blanc, P. and Wald, L.: The SG2 algorithm for a fast and accurate computation of the position of the Sun for multi-decadal time period, Sol. Energy, 86, 3072-3083, doi:10.1016/j.solener.2012.07.018, 2012.

Blanc, P. and Wald, L.: On the effective solar zenith and azimuth angles to use with measurements of hourly irradiation, Adv. Sci. Res., 13, 1-6, doi:10.5194/asr-13-1-2016, 2016. 
Blanc, P., Espinar, B., Geuder, N., Gueymard, C., Meyer, R., PitzPaal, R., Reinhardt, B., Renné, D., Sengupta, M., Wald, L., and Wilbert, S.: Direct normal irradiance related definitions and applications: The circumsolar issue, Sol. Energy, 110, 561-577, doi:10.1016/j.solener.2014.10.001, 2014.

De Miguel, A., Bilbao, J., Aguiar, R., Kambezidis, H., and Negro, E.: Diffuse solar irradiation model evaluation in the North Mediterranean Belt area, Sol. Energy, 70, 143-153, 2001.

Diabaté, L., Blanc, P., and Wald, L.: Solar radiation climate in Africa, Sol. Energy, 76, 733-744, doi:10.1016/j.solener.2004.01.002, 2004.

Geiger, M., Diabaté, L., Ménard, L., and Wald, L.: A web service for controlling the quality of measurements of global solar irradiation, Sol. Energy, 73, 475-480, 2002.

Gschwind, B., Ménard, L., Albuisson, M., and Wald, L.: Converting a successful research project into a sustainable service: the case of the SoDa Web service, Environ. Model. Softw., 21, 15551561, doi:10.1016/j.envsoft.2006.05.002, 2006.

ISO 9060: Solar energy - Specification and classification of instruments for measuring hemispherical solar and direct solar radiation, Instrumental Standard ISO 9060, International Organisation for Standardization (ISO), Geneva, Switzerland, 1990.

Journée, M. and Bertrand, C.: Quality control of solar radiation data within the RMIB solar measurements network, Sol. Energy, 85, 72-86, 2011.

Lefèvre, M., Oumbe, A., Blanc, P., Espinar, B., Gschwind, B., Qu, Z., Wald, L., Schroedter-Homscheidt, M., Hoyer-Klick, C., Arola, A., Benedetti, A., Kaiser, J. W., and Morcrette, J.-J.: McClear: a new model estimating downwelling solar radiation at ground level in clear-sky conditions, Atmos. Meas. Tech., 6, 2403-2418, doi:10.5194/amt-6-2403-2013, 2013.

Long, C. and Dutton, E. G.: BSRN Global Network recommended QC tests, V2.0., BSRN Technical Report, available at: http://bsrn.awi.de/fileadmin/user_upload/redakteur/ Publications/BSRN_recommended_QC_tests_V2.pdf (last access: 29 February 2016), 2002.

McArthur, L. J. B.: Baseline Surface Radiation Network (BSRN), Operations Manual, WMO/TD-No. 879, WCRP/WMO, Geneva, Switzerland, 2004.

Moradi, I.: Quality control of global solar radiation using sunshine duration hours, Energy, 34, 1-6, doi:10.1016/j.energy.2009.09.006, 2009.
Muneer, T. and Fairooz, F.: Quality control of solar radiation and sunshine measurements - lessons learnt from processing worldwide databases, Build. Serv. Eng. Res. T., 23, 151-166, 2002.

Roesch, A., Wild, M., Ohmura, A., Dutton, E. G., Long, C. N., and Zhang, T.: Corrigendum to "Assessment of BSRN radiation records for the computation of monthly means" published in Atmos. Meas. Tech., 4, 339-354, 2011, Atmos. Meas. Tech., 4, 973-973, doi:10.5194/amt-4-973-2011, 2011.

Wald, L., Albuisson, M., Czeplak, G., Bourges, B., Aguiar, R., Lund, H., Joukoff, A., Terzenbach, U., Beyer, H. G., and Borisenko, E. P.: ESRA: European Solar Radiation Atlas, edited by: Scharmer, K. and Greif, J., fourth edition, includ. CD-ROM, published for the Commission of the European Communities by Presses de l'Ecole, Ecole des Mines de Paris, Paris, France, 2000.

WMO: Manual on the Global Observing System. WMO-No. 544. World Meteorological Organization, Geneva, Switzerland, 1981.

WMO: Guide to Meteorological Instruments and Methods of Observation, World Meteorological Organization, WMO-No 8, 7th Edn., Geneva, Switzerland, 2008.

WMO: Manual on Codes, WMO-No. 306, World Meteorological Organization, Geneva, Switzerland, 2010.

WMO/CIMO: International Organizing Committee for the WMO Solid Precipitation Measurement Intercomparison, Final Report of the First Session, Norrkoping, Sweden, WMO Geneva, Switzerland, 1985.

WMO/TD No. 1320/IMOP Report No. 91: WMO International Pyrheliometer Comparison, IPC-X, 26.9-14.10.2005, WMO, Geneva, Switzerland, 2006.

WRC: Sixth international pyrheliometer comparison (IPC VI), Working Report No. 137, 1-18 October 1985, Davos, Switzerland, 1985.

WRC: International pyrheliometer comparison (IPC VII), Working Report No. 188, 25 September-13 October 1995, Davos, Switzerland, 1995.

Younes, S., Claywell, R., and Muneer, T.: Quality control of solar radiation data, present status and proposed new approaches, Energy, 30, 1533-1549, 2005. 